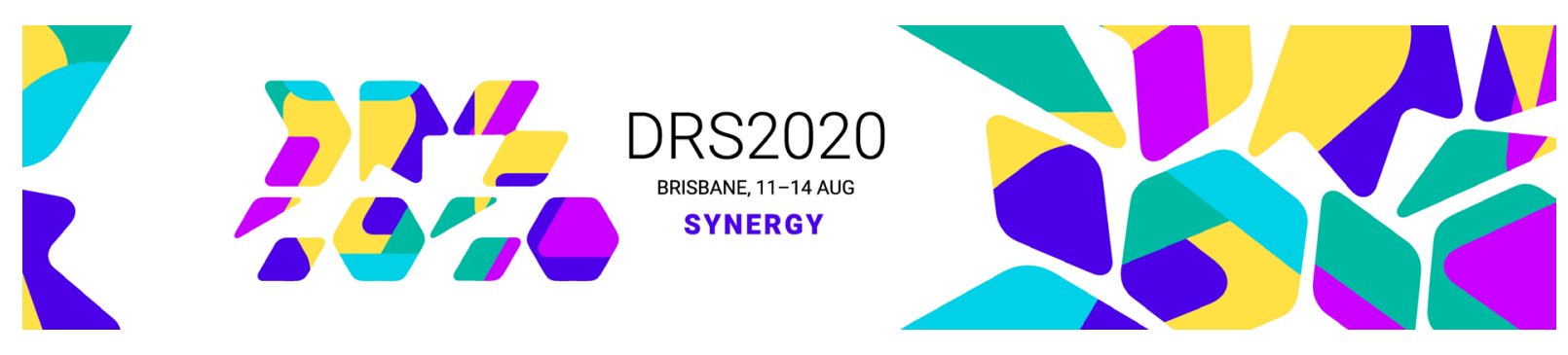

\title{
3D Printing Craft: weaving and oozing
}

\author{
Rina BERNABEI ${ }^{*}$, Jacqueline POWER \\ a University of New South Wales, Australia \\ b University of Tasmania, Australia \\ *Corresponding author e-mail: r.bernabei@unsw.edu.au \\ doi: https://doi.org/10.21606/drs.2020.108
}

\begin{abstract}
This paper explores digital fabrication in the form of 3D ceramics printing. Three iterative case study examples of design work of one of the authors are provided. The case study examples are positioned as research through design, as the designs embody elements of both materials research and development. An underlaying framework of the authors, titled 'user-completion', underpins the discussion and provides a mechanism for developing hybrid design artefacts. Throughout the paper, the notion of craft and risk, which are considered essential aspects of the craft process, are issues also engaged with, and what this means for a digital fabrication process questioned. The intersection of digital fabrication and ceramics facilitates a hybrid design approach, fusing processes and techniques from different disciplinary modes. It is proposed that this provides the opportunity for the discipline to engage in dialogue about the future of disciplinary practice and importantly, its craft.
\end{abstract}

Keywords: digital fabrication; ceramics; craft; hybrid design

\section{Introduction}

The resurgence of craft in main-stream design in recent years, exemplified by designers such as Hella Jongerius, and the rise of online open source platforms for sharing and fabricating files "such as Shapeways in 2007, and Sculpteo and Makerbot in 2009", have refocused interest on craft and its ability to inform digital fabrication processes (Chittenden, 2018,p.13). "Computational digital design allows for new explorations of forms and materials, without the constraints of traditional mass manufacturing. Digital fabrication methods such as 3D scanning, printing and digital CNC and robotics have changed the practice of designers, architects and artists. This new palette of tools has opened the door to the possibilities of new forms and differing levels of engagement for the practitioner" (Bernabei \& Power, 2018, p.120). It has also led to much debate about how digital fabrication, when used in conjunction with or to replace traditional hand-craft practices, transforms the role of the marker and their craft practice.

This paper presents a series of case studies exploring the capabilities of 3D printing and its 
intersection with craft through two specific forms - basketry and ceramics. The paper is written from within the lens of the product design discipline. The first of the case studies Hybrid Material Vessels \#1- took its cues from traditional basketry weaving. In this case study, the hand of the maker and user remains visible and necessary for the finishing of the work. In the second case study, Hybrid Materials Vessels \#2, 3D printing is explored in conjunction with ceramics and the clay body. In Hybrid Materials Vessels \#3, the hand of the maker is removed from the equation altogether (aside from a decorative brass component). This removal of the hand of the maker also reduces the element of risk from the process. Each of the iterations presents an example of 'hybrid design,' which is "a strategy that incorporates elements and processes from diverse fields that are in today's design practice not always perceived as compatible. This is a method to generate new design visions" (Hybrid Space Lab, 2019).

As part of the case study discussion, the role of co-creation in 3D printing and its relationship with craft is unpicked. In particular, co-creation is described in relation to the authors' own design framework called 'user-completion'. The authors have previously discussed this framework and tested it through design prototypes. The user-completion framework requires the user's involvement to be conceived of as part of the design process. This is a co-design model in which a non-expert designer has the ability to make design decisions. In previous versions of this idea, the model focused on a specific moment in the design process - assembly and completion. The 3D printed designs presented as case studies here, shifts the user-completion and participatory element to proceed the point of fabrication, made possible because of 3D printing and digital workflows. Folded into the discussion of applying the user-completion model is the notion of risk-taking and its relationship with craft practice. In this way, the discussion seeks to avoid establishing a binary between digital and analogue craft-based processes, but instead frame 3D printing and its associated digital fabrication workflow as an opportunity to test new models of co-creation, connecting not only designers and non-experts but generating connections across digital and traditional environments.

\section{A comment on craft and 3D printing}

The often-cited definition of craftmanship from David Pye (2002, p.20) links the craft process to notions of risk using the catch-phrase, the "workmanship of risk." In digital fabrication, Zoran and Buechley $(2013$, p.6) note that there is "by definition" no risk - it is entirely removed from the equation. They note that in a digital fabrication process, "a digital design file specifies exactly what a machine should produce; the result is pre-determined by the file" (Zoran \& Buechley, 2013, p.6). While this may be the case for much digital fabrication, this paper will challenge such a proposition through the discussion of 3D printing and ceramics, where much risk remains inherent in the process.

From a product design perspective, it would likely be argued otherwise that risk-taking is entirely absent from a digital fabrication process. A product designer is aware that many risks of various types exist in a digital fabrication process. These risks may not reside at the point 
of fabrication due to their removal in the controlled nature of the tectonics of the material, but rather risk may instead exist in the complex work flows that involves integrating a digital and physical environment. In 3D printing ceramics, there is much risk at the material level and its performance.

Returning to Pye's definition, McCullough (1996, chapter 7) suggests that this definition provides a "fundamental challenge from tradition to the proposition of electronic craft". McCullough (1996, chapter 7) observes in a merger of craft and digital "increased notational density supports quasi-continuous operations formerly only available from physical materials." This ability to manipulate - to iterate - is an important feature present in a designer's process when operating at the intersection between digital fabrication and craft. According to McCullough (1996, chapter 7), "Increased notational density distinguishes computing from earlier allographic media based on manual notations such as text or musical scores, which however rich were neither possible to manipulate in real time nor able to provide a continuum of potential states." 3D printing and ceramics provides a different type of opportunity for real time manipulation and engagement across the iterative design and material processes.

Ceramic 3D printing especially in the technologies developing years, cannot reproduce the somewhat flawless outputs as its traditional 3D printing ancestors. The nature of clay, and the knowledge of this material, requires a craft practitioners experience - wedge the clay too thick/hard and it will come out puffy, wedge the clay too soft and it may not keep its shape and come out too fast, don't wedge enough and trapped air bubbles will cause 'explosions' and deformations in the print. Without a full, tactic appreciation of the material and how to craft it, the design will fail - sides will droop, horizontal surfaces not hold etc. So, in a sense the hand of the maker is very much part of the digital fabrication.

\section{The academic designer and design research}

The case studies presented in this paper are the design work of one of the authors who is described as an academic designer, meaning "a designer who has moved from practice to academia, yet still undertakes practice or design; as the framework for their research" (Bernabei \& Power, 2015, p.55). Elsewhere, the authors have attempted to grapple with the question of the role of the academic designer suggesting:

"The academic designer must work within and answer to the framework of the university, and their creative practice must conform to measurable research expectations. The practice of the academic designer is multilayered and may include undertaking activities such as: grant application, investigation and discovery through designing, written reflection of the practiceresearch, exhibition, integration of new knowledge into studio teaching, and academic peerreview" (Bernabei \& Power, 2015: 56).

To further contextualise design research, we refer to Frayling's (1993/4) tripartite model of design research - research into design, research through design, and research for design. Frayling broadly (and fairly briefly) describes research into design as historical or precedent 
research, research through design as including materials research, development work and action research, and research for design in which,

"the end product is an artefact - where the thinking is, so to speak, embodied in the artefact, where the goal is not primarily communicable knowledge in the sense of verbal communication, but in the sense of visual or iconic or imagistic communication."

The research for design category is colourfully and rightly described by Frayling (1993/4, p.5) as the "thorny one." Frayling's definitions provide a useful mechanism to broadly categorise the variety of research types carried out by academic designers, and situate this within a broad framework. However, the three categories are acknowledged as being somewhat "ambiguous" (Jonas, 2007, p.190). Confusion related to these categories has also arisen due to the variety of coordinating conjunctions used, for instance: into/about and through/ by, which may cause the emphasis to shift. Jonas (2007, p.190) comments that "Friedman increases confusion still further: Frayling did not speak of 'research by design', but rather of 'research through art and design'”. As such, a variety of conjunctions appear in the literature and there is slippage in the application of the categories.

We propose that the case study examples presented here are best framed as research through design, as the work embodies elements of both materials research and form and functional development. The design process provides the structure of the methods of research through design, the conceptual development, materiality and prototyping, all informing exploration and design decisions that are made. Research through design, can be captured throughout the design processes. In these case studies, the methods of design research as defined by Bardzell et al. (2016) are, "Design documents can vary in forms, which includes workbooks, journals, engineering diagrams, sketches ... and rough prototype models". One of the benefits of prototyping is that it may open up new creative possibilities through experimentation with materials and physical forms (Eekhout \& Swieten, 2015, p.3). However, traditional formulations of prototyping and its role are called into question by 3D printing processes. Industrial designer Thorsten Franck has observed that, when 3D printed: "“They are not prototypes because the 'prototype' does not exist anymore [in this context]," said Franck ... "When you print the stool, you are manufacturing it" (InDesign Live, 2017). In this sense, the prototype when 3D printed is high fidelity and removes the element of risk described earlier. Yet, when integrating the printed materials with other materials, or working with clay which has a life of its own, a residual material uncertainty remains risky in that it requires a developed tacit understanding - developed through testing and prototyping to determine the possibility for success. The product design prototype in this way, is arguably an element of craft. To return to Pye's (2002, p.20) definition mentioned earlier:

"craftsmanship...as a first approximation...means simply workmanship using any kind of technique or apparatus, which the quality of the result is not predetermined, but depends on the judgment, dexterity and care which the marker exercises as he works. The essential idea is that the quality of the result is continually at risk during the process of making..." 
In the case study examples that will be described here, the material selection reintroduces risk into the equation. In addition, the application of the user-completion framework also embeds unknown risk, although it would not be fair to align this risktype with craft as it involves engagement with non-designers, as will be described.

\section{User-completion framework}

The user-completion framework was first posed by the authors of this paper in 2012. It is distinct from mass customisation yet similarly allows users to peronsalise their product. Mass customisation expert Piller (2008, p.631), has described how manufacturers should provide toolkits to enable end-users the ability for "defining, configuring, or modifying their individual solution within the given set of choice options." The user-completion framework is seen as distinct and separate from traditional mass customisation approaches in which "configurators" or "knowledge-based software tools that support a potential customer in specifying a product solution within a company's product space and guide the customer through the elicitation process" (Piller \& Wang, 2018, p.18). While we propose a "configuration toolkit" of sorts, it is deployed in a different manner to that used in mass customisation and importantly requires user investment to complete the design (Piller \& Wang, 2018, p.19).

The user-completion framework has been tested in a number of designs, including in a workshop run with users to gauge its level of success (see Bernabei \& Power, 2015). The user-completion approach requires the designer to conceive of the product as a kit-of-parts that can be assembled and personalised by the user.

\footnotetext{
"The user-completion approach relies on the specialised skills of the designers to provide the components and understand the manufacturing options, whilst leaving some details of the finished product to the end-user to decide upon. It should be noted that the skill of the designer is in no way diminished by embracing the involvement of the end-user - instead, the designer is required to understand the product in new ways and forecast its potentialities". (Bernabei \& Power, 2018, p.126)
}

Importantly, the various skill levels of the user need to be taken into consideration when designing the kit-of-parts. Mugge, Schoormans and Schifferstein $(2009$, p.473) in a discussion of personalisation, has noted that if a user is not sufficiently skilled to personalise the product, it may be ruined and its value diminished. This is an element of risk that needs mediating by the designer during the design development process.

In response to this possible issue, in the user-completion framework the kit-of-parts is complimented by a pattern 'sheet'. The patterns provide users with possible completion options or may act as inspiration for their own pathway in completing and personalising the product. In a mass customisation model, Piller and Wang $(2018$, p.21) propose "combining a recommendation system with a co-design toolkit" to help with the decision-making process. The pattern sheet provides recommendations in the form of precedent-style examples in this way. The authors understand that for the particular case studies we provide, the end-user would need to have sufficient digital design skill to undertake the printing of the project to 
produce an aesthetically pleasing object. Currently these skills are not widely practiced by the general public but home digital fabrication is on the rise.

\section{Hybrid Material Vessels \#1}

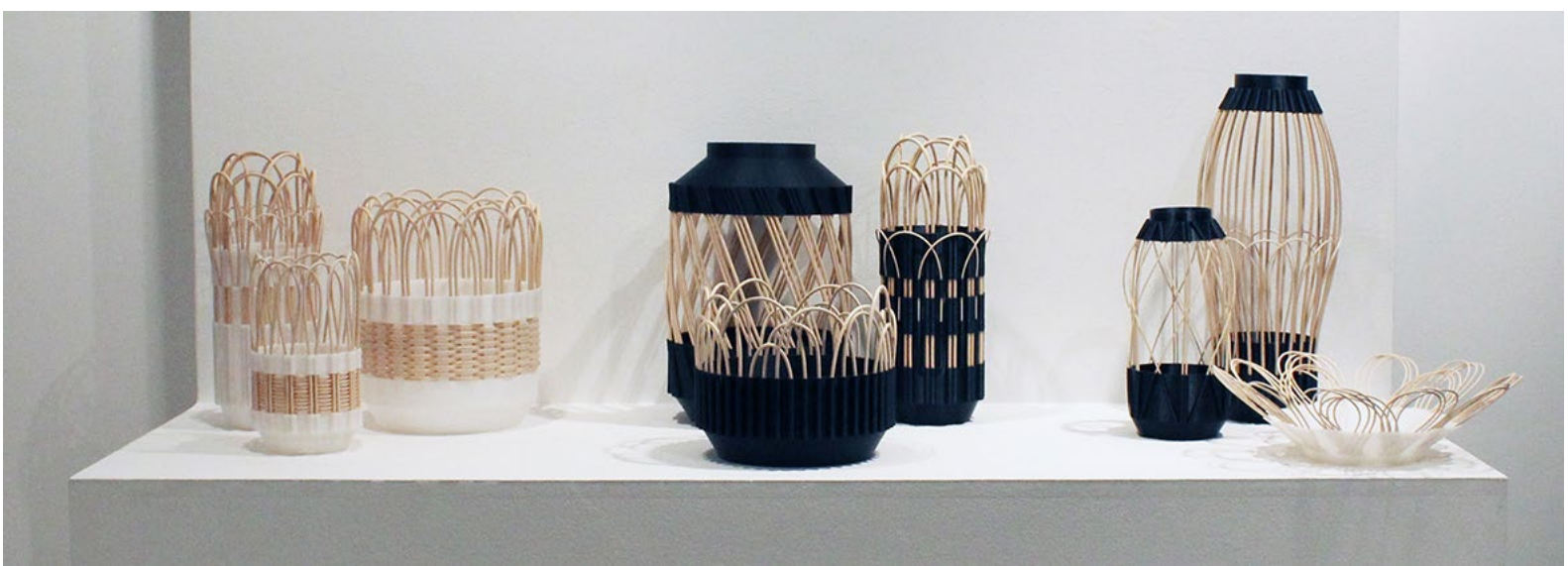

Figure 1 Variations of Hybrid Material Vessels as exhibited in Digital Crafts as part of Sydney Design Week 2018.

This series of Hybrid Material Vessels (Figure 1) were exhibited as a solo show: Digital Crafts as part of Sydney Design Week 2017. The series sought to test the user-completion model in a 3D printing digital fabrication process.

In this first iteration of vessels, the potentiality of basketry and its incorporation with 3D printing was seen as an opportunity. "Basketry and weaving are ancient crafts and have a lot of plasticity- allowing for varying levels of engagement" (Bernabei \& Power, 2018, p.126). A similar observation was made by Zoran (2013, p.326) noting that "These qualities of basketry (adaptability, changeability, and usage of a variety of technologies and raw materials) make it a perfect domain for experimentation."

The initial design developed following an analogue process of hand drawing. To test assumptions, a series of clay models were then made. Importantly, physical prototypes focusing on the "transition points of the vessels - where the rattan meets the digital print - were experimented with both digitally and through the clay models. The early designs mimicked traditional woven forms, with the idea that the rattan or flexible element would appear to 'grow' from the digital vessel. These initial forms were abandoned, and after more form development a more industrial language was adopted for the 3D component of the vessel" (Bernabei \& Power, 2018, p.127).

The tool used for printing the vessel was an extrusion-based printer [Up Printer 2] whose process involves "a thin plastic filament...fed into an extruder, which melts the filament and lays down a thin trail of plastic onto the build plate" (Chittenden, 2018, p.13).

The material selection was two-fold. One was the selection of material for the 3D-printed form and the other the woven material element (Figure 2). For the 3D-printed form, ABS 
material was selected because of its being economic and readily available. For the woven element, "Traditional rattan was chosen for the woven element - as it holds a strong traditional visual language and was available in many sizes" (Bernabei \& Power, 2018, p.127).

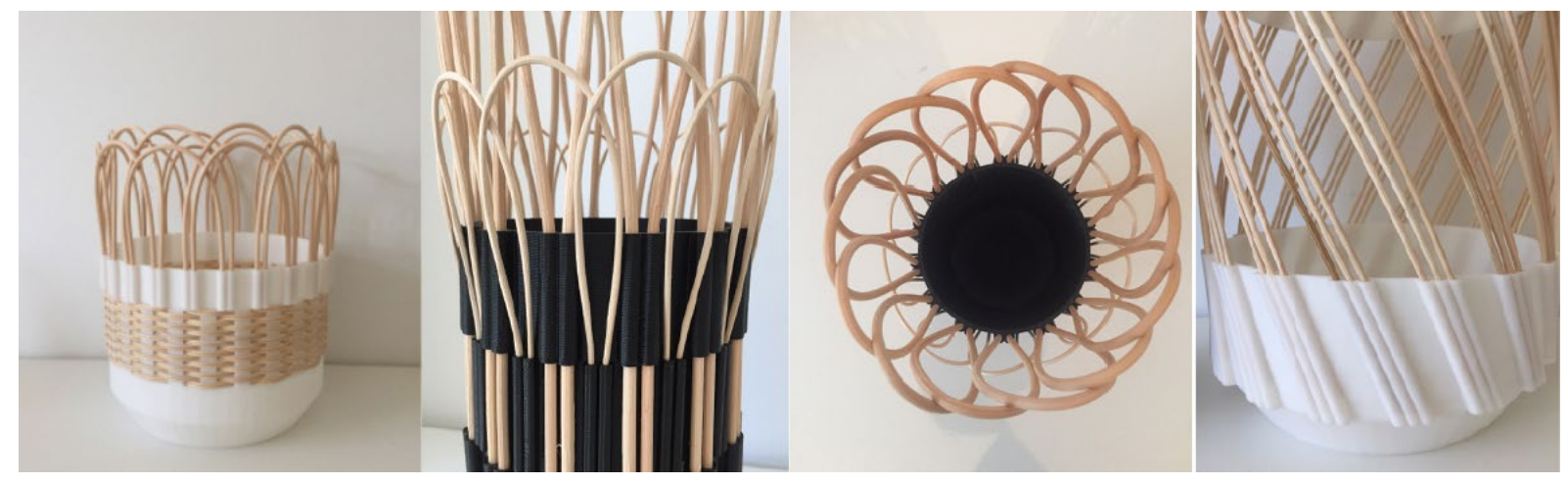

Figure 2 Details of the Hybrid Material Vessels, variations in printed components and rattan weaving.

In developing the forms of the vessels, they "were not, and could not, be entirely preconceived. The act of 'crafting', through the basket weaving, was dependent on many unknown quantities - the materials available and their constraints, the 'mood' of the maker, the time involved in fabrication. This is what links it back to the essence of craft" and Pye's notion of risk-taking as inherent in the process (Bernabei \& Power, 2018, p.127). However, it is important to acknowledge that the element of risk remains firmly situated in the handcrafted component of the vessels. From a fashion design perspective, Kate Fletcher and Lynda Grose (2012, p.146-47) emphasise the tacit material knowledge associated with craft practice:

"hands-on, resource based and practical. It has a visceral connection with materials and the way they are shaped into forms for display or use. It involves the actual doing of something rather than merely the experience of being done to - that is, the practice".

The user-completion framework underpinned the conceptual development of the vessels. In a digital fabrication process facilitated by 3D printing, it was envisaged that if the final vessels were developed for the marketplace, the user would receive the file for the vessel as an STL file. They would then have the option to customise the vessel in a material of their choice with resulting implications for colour, texture and weight. Scale changes could also be made. The user could then either print at home or through an online agency. This level of customisation is made possible by receiving the file itself not simply the end product. Of course, this presupposes that the user has access to a suitable CAD platform. "Users could have weaving diagrams [patterns] available (through a web source) to mimic, or they could weave their own design. The design of the vessels allows for different flexible materials to be slotted into the 'tubes' of the vessel wall. This means the user could use organic and/ or synthetic filaments or other materials, such as metal, to vary colour, texture and visual language" (Bernabei \& Power, 2018, p.127). The notion of risk described by Pye remains ever present for the user and the variety of decisions they might make and the implications 
these decisions will have on the finished vessel. Without a practiced craft-hand, a user will be unlikely to be able to assess and manage the risk.

\section{Hybrid Material Vessels \#2}

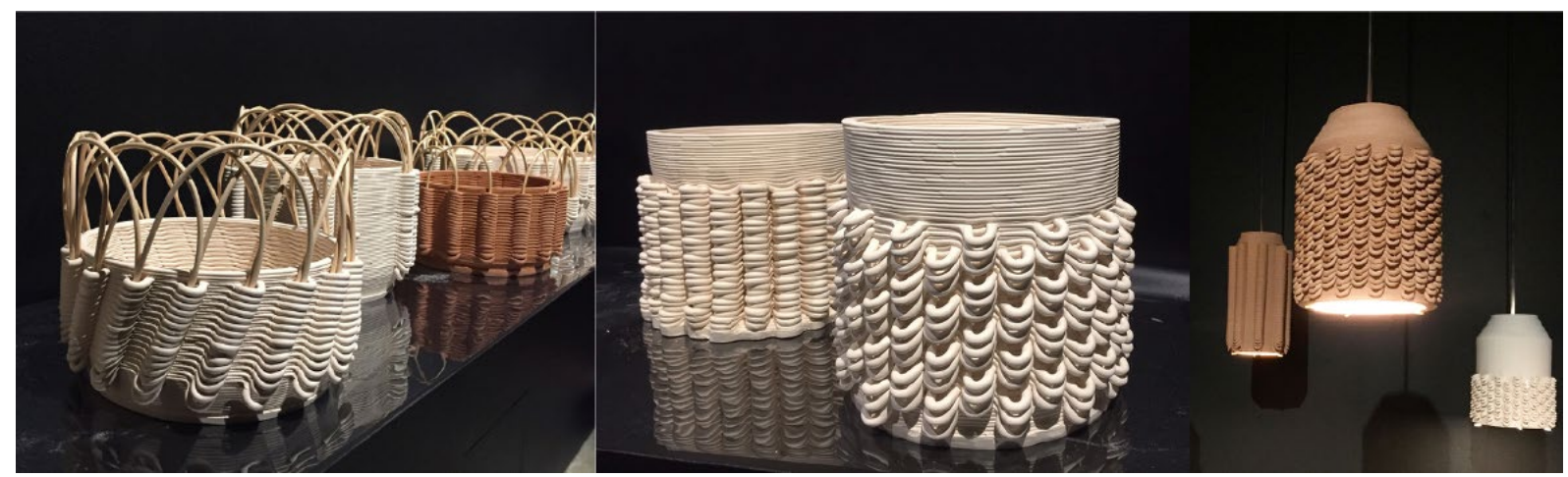

Figure 3 Woven rattan and 3D printed ceramic vessels exhibited as part of the Woven Dialogues exhibition at UNSW Galleries, Sydney 2018.

This series comprised 3D-printed earthenware and terracotta with interwoven rattan (Figure 3). Exhibited as part of Woven Dialogues, at UNSW galleries in 2018.

As with Hybrid Material Vessels \#1, the objects are produced through digital design and fabrication and then completed through hand-craftwork. The digitally designed and fabricated components are themselves an exploration of both traditional and emerging new manufacturing methods. This case study of design practice, reflected on the process of designing for both craft and digital fabrication, from the experience gained with the earlier traditional $3 \mathrm{~d}$ printed vessels.

In this iteration, 3D printed ceramics was selected as the material of choice, with the aim to recreate the vessels using ceramic to give them a perceived high material value, and weight. This was the authors first experimentation into ceramic 3D printing, and while in many senses the process of digital design was similar to 3D printing, the nature of clay changed the fabrication process and results drastically. "Clay is wet, messy and respond to gravity under its own weight. It is possible for nozzles to over-ooze, to get clogged, for printed layers to sag if printed too quickly or to fall apart if layer are too dry" (Chittenden, 2018, p.15. The resulting vessels capture the imperfections of the making process in their haphazard irregularity and visual gravitational indicators. They are much more aligned with craft practice and the improvising nature of making. 


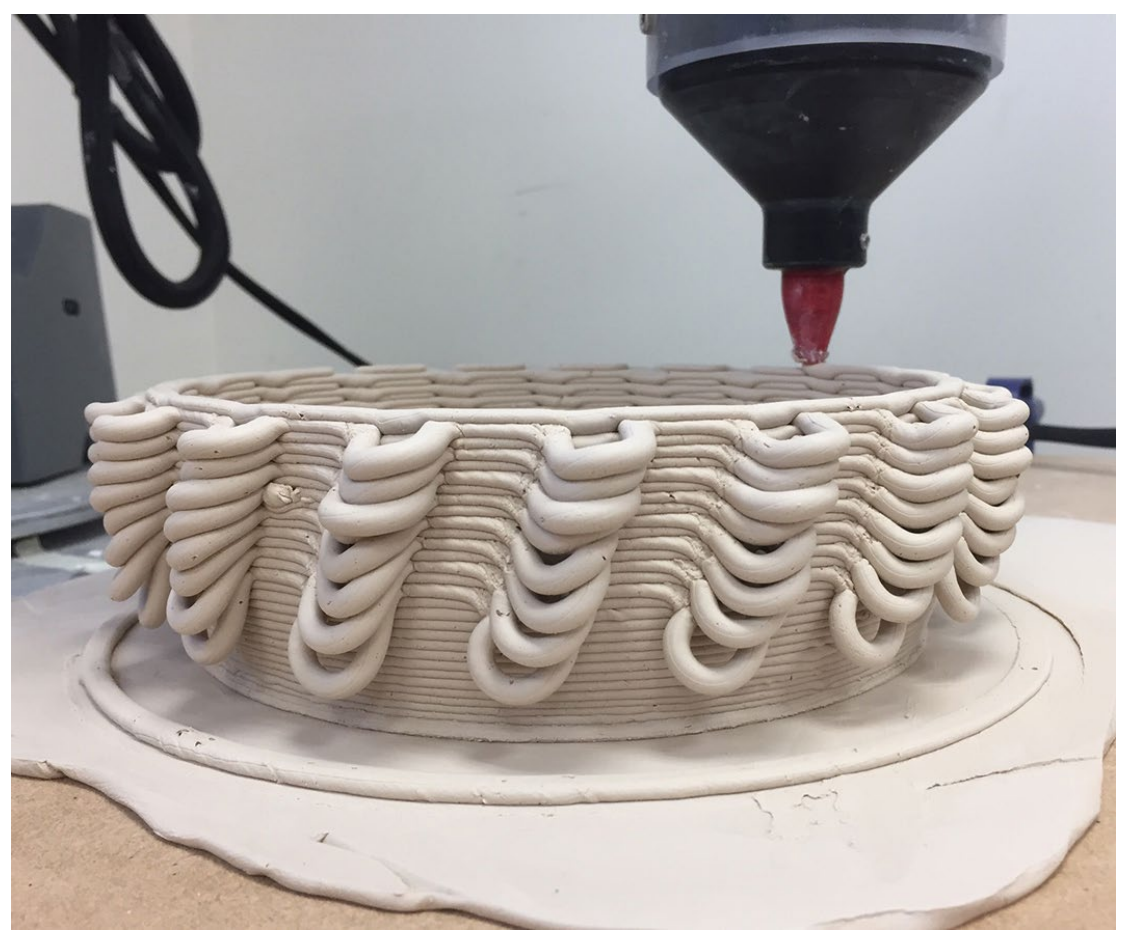

Figure 4 Ceramic 3D printing of the Hybrid material vessels \#2, clay loops can be seen "drooping" as it is pushed out of the Potterbox printer, due the loops being unsupported and the forces of gravity.

As the designer/author had no prior experience working with clay, she undertook a 4-week ceramic course to learn the basics of wedging, hand building, clay recycling and the firing processes. It became evident early on in the concept stage, that the designs from Hybrid Material Vessels \#1, could not simply be reproduced in ceramics; the digital drawing was vastly diverse, the 'drawing' did not give any clear indication of what the resulting fabrication would perform like, or look like. The digital interface between the user and the ceramic printer - the Potterbox, is very primitive, with pixelated icons representing the designs. The line drawing, does not take into consideration the nozzle size used on the printer, nor the spread of the clay as it prints and impacts on each layer - so measurements were vague, and radii unknown. Air bubbles were explosions that deformed or destroyed the print entirely. Bases needed to be hand rolled as the printed base was not strong enough, and once the vessel was leather dry, the bases needed to be trimmed before bisque firing. Through this experience, it can be said that the process of digital 3D ceramic printing is a combination of ceramic hand building and finishing, alongside digital fabrication.

"Yet clay is still unpredictable enough to make its voice heard in dialogue with the requirements of the printer - certainly in the coil extrusion approach...The ways in which the material can distort the intended print, rather than being seen as a frustration of failure, has suggested ways for some practitioners to reintroduce the humanness in printed forms and led them to deliberately program random noise into some of their prints" (Chittenden, 2018, p.21).

Due to the imperfections and irregularities of the print, especially with the 'loops' (Figure 4), 
and the shrinkage in both the bisque and final firing, tolerances were difficult to calculate, which effected the rattan weaving component of the designs. In Hybrid Material Vessels \#2, the weaving is far more simplified than in the first series of vessels, but as the design is so decorative due to the clay printing, the designer decided to leave off weaving in some of the vessels.

Questions of 3D printing and craft (in cases where the final artefact is considered to be aligned with craft and therefore bespoke, not in the situation of 3D printed mass-produced multiples), reveals the need to ask broader, potentially disciplinary re-shaping questions. Chittenden $(2018$, p.36) proposes a number of thought-provoking questions, particularly in relation to the ownership and exhibition of 3D-printed craft objects, asking;

"Can individuals print their own Edmund de Waal from file? Do galleries maintain control of print-on-demand runs? Would we see counterfeit 3D scans produced in numbers? Would a museum print a version of a ceramic work for exhibition, meaning that the file is transported rather than a fragile object? What does 3D printing mean for insurance claims if a broken original can be reprinted from file?"

Some of these questions stem from the underpinning concern for the authenticity of the original and how this may be eroded by the 3D printing process. At the root of these questions is something akin to the Ship of Theseus paradox - what does identity and originality mean when components or whole artefacts can be replaced? Is there a point of loss where the craft-'ness' vanishes? This presents an intriguing disciplinary risk of a different nature.

Reflecting on these thoughts from Chittenden, the framework of user-completion has the potential to open out the actors interacting with the designs - to expand beyond the domestic users, as the framework is largely currently conceived, to include galleries and professional design organisations. In this way, the user-completion framework could be made more robust through the more detailed consideration of 'users' and who these might entail and what their needs might be. The user-completion framework in this iteration was employed in a similar manner to the earlier iteration but in the vessels that did not include this component, the user does not have the same degree of involvement or investment in completing the design. 


\section{Hybrid Material Vessels \#3}

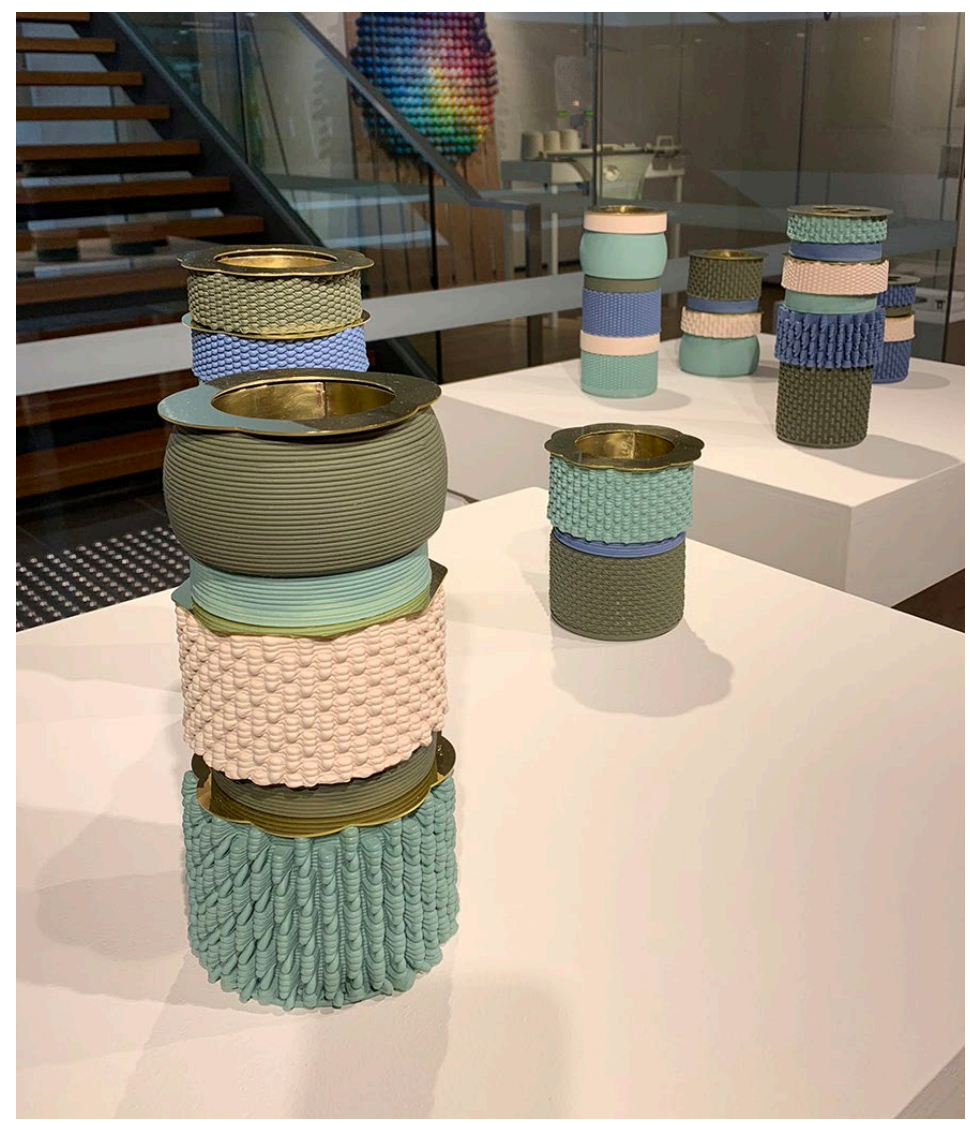

Figure 5 Hybrid Material Vessels \#3 exhibited as part of the Femufacture exhibition at the Japan Foundation, Sydney 2019.

This series comprised 3D-printed tinted stoneware ceramic vessels with brass sheet collars exhibited as part of the Femufacture exhibition in 2019 (Figure 5).

The author set the brief to merge traditional decorative and craft forms and qualities, with those of digital fabrication. Using domestic Australian ceramic decoration of the $60 \mathrm{~s}$ and $70 \mathrm{~s}$ as a reference point and reinterpreting these through digital design software and 3D ceramic printing fabrication, the vessels were completed with handmade brass components. The design and production process examined the contradictions and similarities of traditional domestic decoration and forms, and the new visual and formal language of 3D ceramic digital fabrication.

The vessels in this iteration take on a much more mechanical feel, more aligned with traditional 3D printing. In part, this is the outcome of design intent, but also as a result of the designer/author having a greater understanding of the 3D ceramic printing process and the nature of the clay after working on Hybrid Material Vessels \#2. In this way, the designer built tacit craft knowledge through lived experience of the process. The vessels were designed with this understanding and also to capture the decorative patterning qualities of the layering process. 


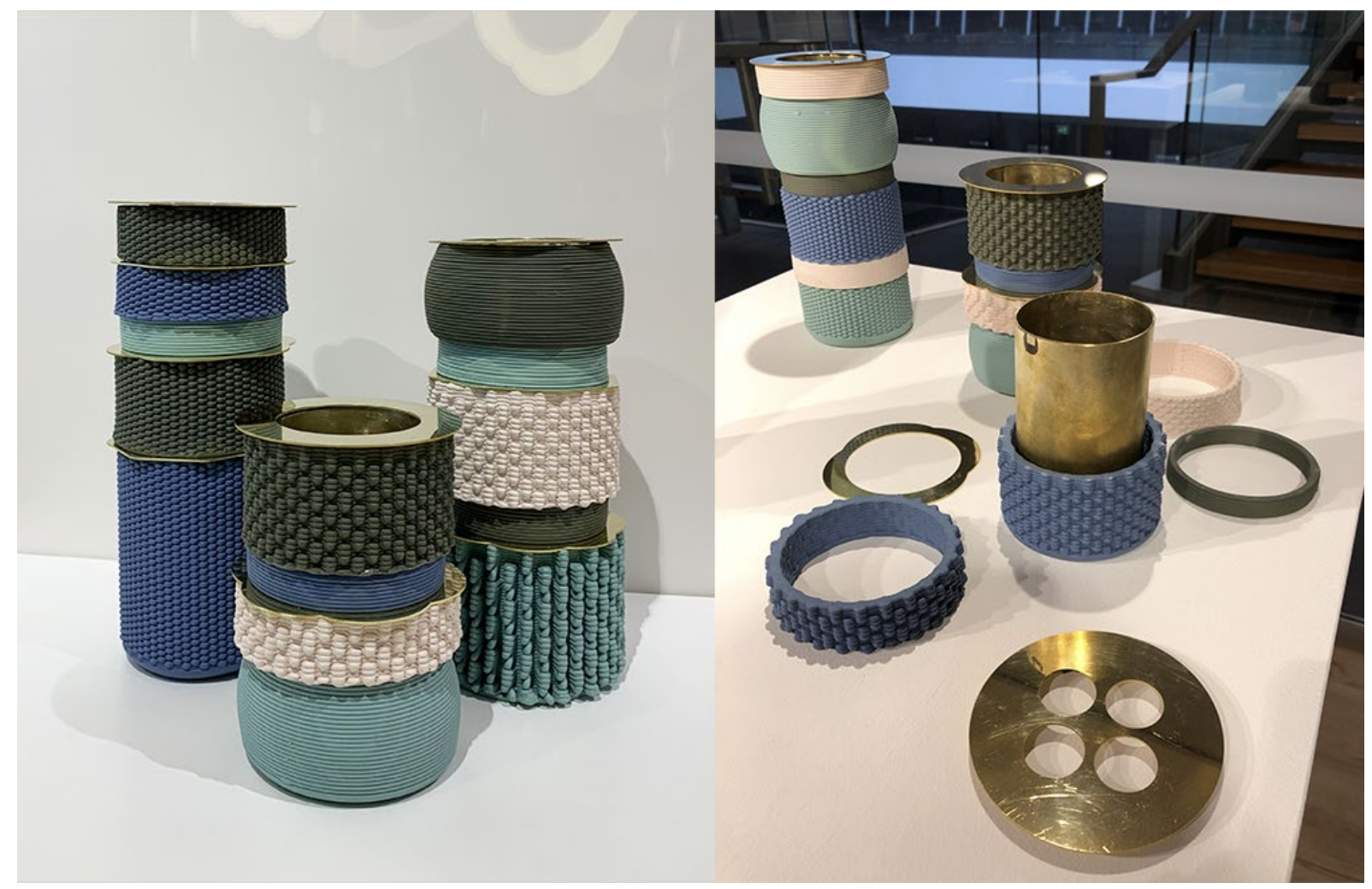

Figure 6 Each component of the vases is layered over a central brass vase, allowing the user to achieve different configurations and a sense of personalisation.

In keeping with the authors' "user completion framework", the vessels were designed with a playful user interaction component. Each vessel had a hand-fabricated brass inner vase, and a series of brass collars. Each ceramic component was printed separately using different colour tinted clay, and different pattern configurations - like bangles that could be slipped over the metal inner vase in multiple configurations (Figure 6). The design intent being that the end user is able to design the final vase using the ceramic bangles and brass collars in whatever arrangement they preferred. As a result, the user involvement is more controlled and reduces the level of risk when engaging with the object.

\section{Conclusions}

Through Vessels \#2 and \#3, the designer/author's experience of digital fabrication was challenged due to the material choice of clay. Chittenden (2018, p.15) acknowledges that "the relationship between 3D printers and typical ceramic ware has been a strained one." This is perhaps unsurprising because as McCullough (1996, chapter 7) has said, historically "any dominance by or widespread commercial use of a powerful new technique tended to taint its acceptance in the artistic academy". However, the foundation of distrust between 3D printing and ceramic practice emerged from early difficulties of printing at a satisfactory scale, difficulties of printing food-grade and heat safe materials, and challenges of working with clay in a printed. It is still a medium that one cannot receive satisfactory results, without 
experience - or craftmanship of clay and ceramic practice. In a sense, the process has really been a 'crafting of digital fabrication.' While ceramic 3D printing can produce 'identical' artefacts, the process more often than not produces artefacts that all have individuality due to the nature of the wet clay, and like handmade ceramics, they all slightly vary and warp through the drying and firing process. The authors also felt that the layering method of fabrication also has many more limitations than traditional 3D printing. In traditional digital fabrication, support walls are often printed, that can then be removed once the print is complete. However, this is not possible in ceramic printing, therefore any overhangs or horizontal surfaces cannot be supported and collapse or droop. In addition, forms in general need to be more 'vertical', and radii and curves need to be very gentle so that the layers of wet clay support themselves without toppling.

The authors' user- completion method applied to a digital fabrication process encouraged hybrid design to occur. The intention here was to involve the user in the finishing and assembly processes, which encourages a craft-like approach. The author chose a basketry crafting process to facilitate the user involvement, but it is acknowledged that many types of craft practices are open to user involvement. The user-completion method seemed to offer a good approach for developing hybrid artefacts, allowing the machine and the craftsperson to work together. This type of approach has the potential to avoid "a false dichotomy between digital and physical processes," and instead encourage a process where "designers might operate in a post-digital environment, where the boundary between screen and workbench has dissolved completely" (Chittenden, 2018, p.36). It also facilitated a hybrid design approach, fusing processes and techniques from different disciplinary modes, in this case, digital fabrication and craft. The potential of this approach is "a method to generate new design visions" that also allow the disciplines to engage in dialogue about new techniques and their implications for the future of the disciplinary practice and its craft (Hybrid Space Lab, 2019).

\section{References}

Bernabei, R. and Power, J. (2018). Hybrid Design: combining craft and digital practice. Craft Research, 9(1), 119-134.

Bernabei, R. and Power, J. (2015). Illuminating Design Research: shining light on the academic designer. IDEN, 3, 55-75.

Bernabei, R. and Power, J. (2013). Designing Together: end-user collaboration in designing a personalised product, Available online: http://www.craftingthefuture.se/ 10th European Academy of Design Conference - Crafting the Future.

Bardzell, J. and Bardzell, S., Dalsgaard, P., Gross, S. and Halskov, K. (2016). Documenting the Research Through Design Process. Proceedings of DIS2016, pp. 96-107. ACM: New York.

Chittenden, T. (2018). Printed Pots and Computerized Coils: the place of 3D printing in ceramic practice. Craft Research, 9(1), 9-40.

Eekhout, M. and Swieten, P. van (2015). The Delft Prototype Laboratory, Research in Design Series, vol. 8, IOS Press. 
Fletcher, K. and Grose, L. (2012). Fashion \& Sustainability: design for change. London: Laurence King Publishing.

Frayling, C. (1993/4). Research in Art and Design, Royal College of Art Research Papers, 1:1, 1-5.

Hybrid Space Lab. (2019). Beijing Design Week Lecture Hybrid Design 14.00-15.00, 27 September 2015 @ Media Lab Central Academy of Fines Arts Beijing. Retrieved from: http://hybridspacelab. net/hybrid-design/ Accessed 11 November 2019

InDesign Live. (2017, March 15). The Wilkhahn PrintStool One: 3D Printing Just Levelled-Up!'.

Retreived from https://www.indesignlive.com/the-goods/wilkhahn-printstool-one-3d-printing-justlevelled Accessed 17 October 2019.

Jonas, W. (2007). Design Research and its Meaning to the Methodological Development of the Discipline. In Michel, R. (Ed.). Design Research Now: essays and selected projects, pp. 187-206. Basel: Birkhauser.

McCullough, M. (1996). Abstracting Craft: The Practiced Digital Hand, Cambridge, MA and London: The MIT Press.

Mugge, R., Schoormans, J. P. L, and Schifferstein, H. N. J. (2009). Emotional bonding with personalised products. Journal of Engineering Design, 20(5), 467-476. doi: 10.1080/09544820802698550

Piller, F. T. (2008). Observations on the present and future of mass customization. International Journal of Flexible Manufacturing Systems, 19(4), 630-636. doi: 10.1007/s10696-008-9042-z

Piller, F. T. and Wang, N. (2018). Product Configurators: tools and strategies for the personalization of objects, London: Routledge.

Pye, D. (2002). The Nature and Art of Workmanship, Cambium Press.

Zoran, A. (2013). Hybrid basketry: Interweaving digital practice within contemporary craft.

Leonardo, 46:4, 324-31.

Zoran, A. and Buechley, L. (2013). Hybrid Reassemblage: an exploration of craft, digital fabrication and artifact uniqueness. Leonardo, 46:1, 4-10.

About the Authors:

Rina Bernabei is a Senior Lecturer in the Industrial Design program at the University of New South Wales. In 2003, she co-founded Bernabeifreeman with Kelly Freeman; a furniture/object design company that has received wide acclaim nationally and internationally.

Jacqueline Power's research explores notions of interior, interiority and cosmology in relation to classical Australian Indigenous buildings. She also undertakes collaborative product design research. Jacqueline's research has appeared in journals such as Craft Research, the Journal of Interior Design and Fabrications. 